\title{
Mental foramen of Human Mandible: Morphometric Study
}

\section{Ndiaye M R ${ }^{* 1}$, Mar N B ${ }^{2}$, Yacouba Garba K ${ }^{3}$, Ndoye J M N 4 .}

${ }^{*} 1$ Senegalese Armed Forces Health Service, Avenue des Jaambars Camp Dial DIOP BP 4042 Dakar, SENEGAL.

${ }^{2}$ Anatomy Laboratory Iba Der THIAM University of THIES, Cité Malick SY, N2 BP: A967 Thiès, SENEGAL.

${ }^{3}$ Anatomy Laboratory Assane SECK University of ZIGUINCHOR, Diabir, BP 523 Ziguinchor, SENEGAL.

4 Anatomy and Organogenesis Laboratory Cheikh Anta DIOP University of Dakar, Faculté de Médecine UCAD, Fann BP 5005 Dakar, SENEGAL.

\section{ABSTRACT}

Aim: The aim of our study was to perform a morphometric analysis of the mental foramen in senegalese context.

Material and method: The study was performed on thirty-nine dry mandibles of adult humans. On these mandibles, the number of mental foramen present and their shape were noted on inspection. The situation of the foramen in relation to the lower teeth was studied according to a methodology already described. The following measurements were made: the distance between the foramen and the other landmarks of the mandible (symphysis, basilar border, posterior border), vertical and horizontal diameters.

Results: The number of mental foramina were 39 on the right and 40 on the left: one mandible presented a double foramen on the left. The oval shape was predominant. The most frequent situation was below the second premolar on both sides. The mean distance between the foramen and the mandibular symphysis was $25 \mathrm{~mm}$ on both sides. The distance between the foramen and the basilar border of the mandible was on average $13 \mathrm{~mm}$ on the right and $14 \mathrm{~mm}$ on the left. The distance between the foramen and the posterior border of the mandible was on average $72 \mathrm{~mm}$ on the right and $73 \mathrm{~mm}$ on the left. The average vertical diameter was $33 \mathrm{~mm}$ on the right and $32 \mathrm{~mm}$ on the left, and the average horizontal diameter was $4 \mathrm{~mm}$ on both sides.

Conclusion: Mental foramen is a constant anatomical structure, found on all the mandibles studied. The results can be superimposed on those described in the majority of studies carried out on the mental foramen.

Key words: Mental Foramen, Mandible Anatomy, Morphometry.

Corresponding Author: NDIAYE Mame Rouba, Senegalese Armed Forces Health Service, Avenue des Jaambars Camp Dial DIOP BP 4042 Dakar, SENEGAL.

E-Mail: ndiayemamerouba@gmail.com

\section{Access this Article online}

Quick Response code

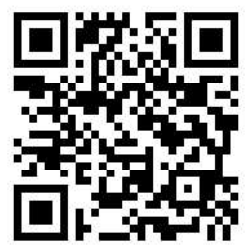

DOI: $10.16965 /$ ijar.2021.164

\begin{tabular}{|c|c|c|}
\hline \multicolumn{3}{|c|}{ Journal Information } \\
\hline $\begin{array}{r}\text { International Journa } \\
\text { ISSN (E) 2321-4 } \\
\text { https://wn } \\
\text { DOI-Prefix: https }\end{array}$ & $\begin{array}{l}\text { Anatomy and Res } \\
\text { ISSN (P) 2321-8967 } \\
\text { hr.org/ijar.htm } \\
\text { doi.org/10.16965/ijar }\end{array}$ & $( \mathrm { cc } ) \longdiv { \mathrm { EY } - \mathrm { MC } - \mathrm { BH } }$ \\
\hline \multicolumn{3}{|c|}{ Article Information } \\
\hline Received: 29 Aug 2021 & \multicolumn{2}{|c|}{ Accepted: 05 Oct 2021} \\
\hline Peer Review: 30 Aug 2021 & \multicolumn{2}{|c|}{ Published (O): 05 Dec 2021} \\
\hline Revised: None & \multicolumn{2}{|c|}{ Published (P): 05 Dec 2021} \\
\hline
\end{tabular}

level of the chin, the oral commissure, the lower lip, the gum and the vestibular mucosa of the second premolar up to the central incisors [2].

FM is located at the level of the body of the 
mandible, equidistant between the upper border and the lower border $[3,4]$, in dentate adults. However, positional variations are reported by some authors in different ethnic groups $[5,6]$. Variations in shape have also been noted [7]. The study of the mental foramen has several interests.

Identifying the precise anatomical situation is very important for dentists in endodontic treatment $[8,9]$, periodontal surgery [10], surgical orthodontics $[6,2]$, pre-prosthetic surgery $[11,12]$ and in other areas. It is also important in maxillofacial surgery and aesthetic surgery. Indeed, the ignorance of its anatomy and its variations can lead to the accidental section of the mental nerve, during an intervention and be at the origin of permanent sensory losses at the level of the perioral soft tissues.

She also has an interest in the realization of the anesthetic block of the mental nerve. During unilateral anesthesia of the lower lip and chin to suture a labial wound, the path of the nerve and therefore its point of emergence (FM) must be taken into account.

On the aesthetic level, to treat an injury by laceration of the lower lip, chin or labial gum, the surgeon must often perform an anesthetic block of the mental nerve which is preferred to an infiltration anesthesia in order to prevent sequelae afterwards wound healing [13].

The aim of our study is to perform a morphometric analysis of the mental foramen in adults in the senegalese context.

\section{MATERIALS AND METHODS}

Framework and study period: This is a two-center study. It took place simultaneously at the Laboratory of Physical Anthropology and Cultural Engineering of the Fundamental Institute of Black Africa (IFAN) and at the Laboratory of Anatomy and Organogenesis of the Faculty of Medicine of the University Cheikh Anta Diop de Dakar (UCAD), over a six-month period.

Study sample: The study involved thirty-nine dry mandibles from adult subjects. Nine mandibles belonged to the Laboratory of Anatomy and Organogenesis of UCAD and the other thirty to the Laboratory of Physical
Anthropology and Cultural Engineering of IFAN. The age and sex of the subjects whose mandibles were studied were not specified.

Inclusion and non-inclusion criteria: We included in our study all adult dry mandibles without resorption of alveolar bone. The deteriorated mandibles, therefore unusable for the study, were not included.

Measuring tools: We used a double-pointed compass, a graduated ruler and a tape measure.

Methodology: This was a comparative descriptive study. We list all the mandibles meeting the inclusion criteria for our study and the final sample was selected. The bone points and landmarks for measurements were clearly defined by two operators and the measurements carried out simultaneously by the latter.

For each mandible, we studied:

- the number of mental foramina present;

- the shape of the mental foramina;

- their position in relation to the lower teeth;

- their situation in relation to the mandibular symphysis;

- their location in relation to the posterior edge of the ipsilateral mandibular branch;

- their location in relation to the basilar border of the body of the mandible.

The vertical and horizontal diameters of the mental foramina were also measured. The number and shape of the foramen was determined upon inspection. The position of the foramen relative to the lower teeth was assessed relative to one of five longitudinal axes passing through the apex of the teeth or the interdental spaces (Figure 1).

When the foramen was too small, not belonging to any of the predefined axes or too large belonging to two different axes, it was then considered to belong to the most anterior axis, as recommended by Green [5].

To determine the distance between the mental foramen and the mandibular symphysis on the one hand and the distance between the foramen and the lower edge of the mandible on the other hand, we used a method defined by Morrant [4]. The mandible 
was placed on a horizontal plane and held in place by vertical pressure exerted on the second molar. A plane parallel to this standard plane was used to perform the measurements. It passed through the middle of the mandibular symphysis, through the foramen and crossed the posterior edge of the branch of the mandible. The distances foramen-symphysis and foramen-posterior edge of the branch of the mandible were measured on this plane.

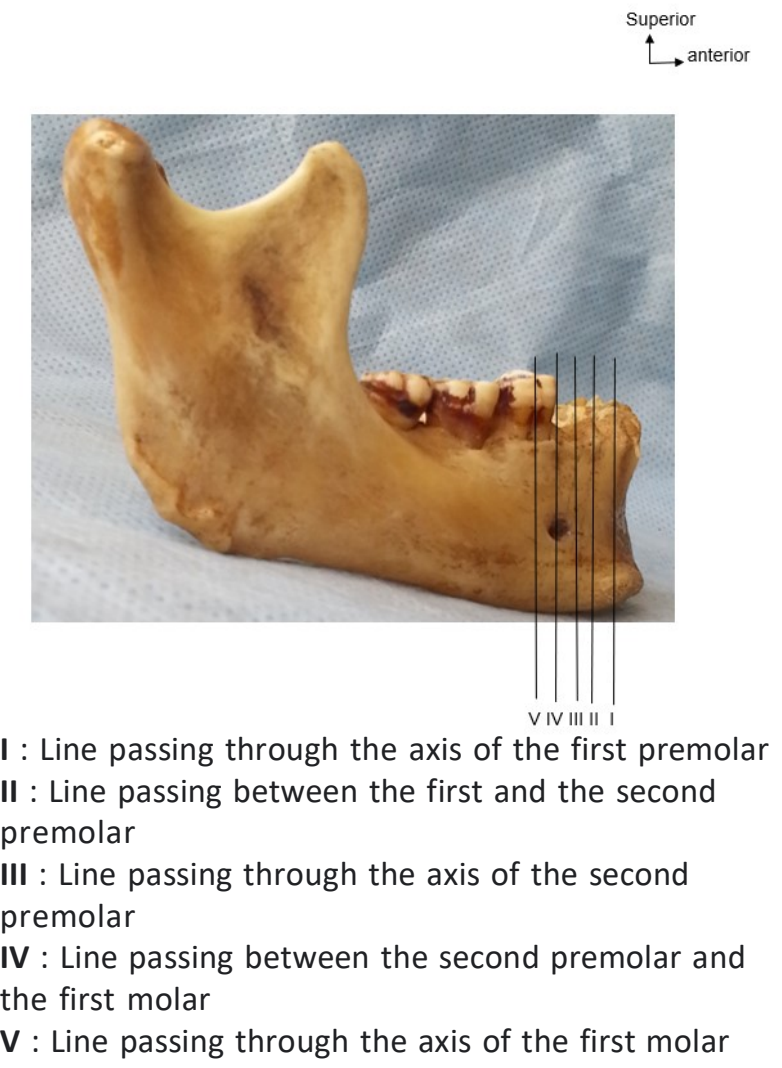

Fig. 1: Classification of the situation of the mental foramen in relation to the lower teeth.
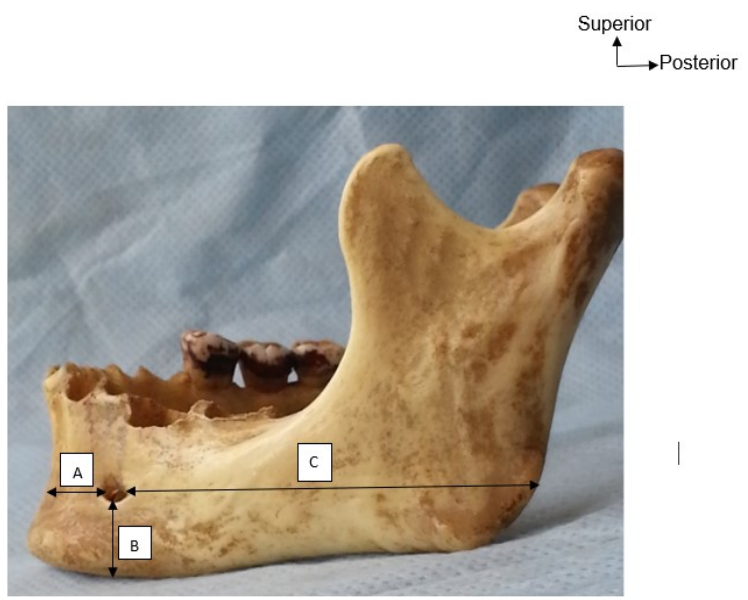

Fig. 2: Position of the mental foramen in relation to the mandibular symphysis $(A)$, the lower border of the body of the mandible (B), the posterior border of the mandible (C)
The distance between the anterior limit of the foramen and the mandibular symphysis was defined as $A$. The distance between the lower limit of the foramen and the basilar border of the mandible was named $B$. The distance between the foramen and the posterior border of the mandible was named C (Figure 2).

All distances were expressed in millimeters $(\mathrm{mm})$. For data collection, we used a pre-established form. The data collected was recorded and analyzed on Excel software.

\section{RESULTS}

The number: We found 79 mental foramina out of the 39 mandibles studied. In our series, $97.44 \%$ of the mandibles presented a foramen on the right as well as on the left (Figure 3).

One mandible presented a double foramen on the left (Figure 4).



Fig. 3: Right and left mental foramina on an anterior view of a mandible.

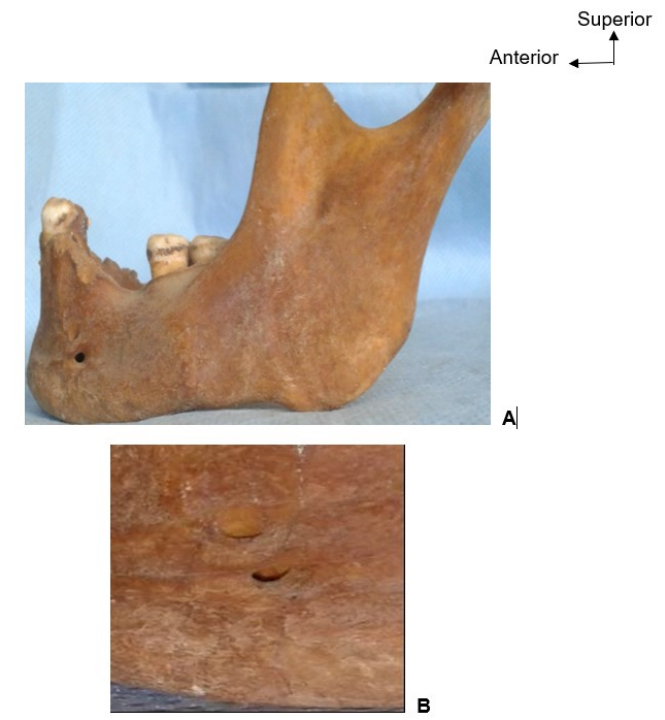

Fig. 4: Double mental foramen on a left lateral view of the mandible

A. Entire mandible B. View centered on the foramina 
The form: The foramina observed were round (Figure 5) or oval (Figure 6). On the right, the oval shape was found on 32 mandibles (82\%) and the rounded shape on $7(18 \%)$. On the left, of the 40 foramina found, the oval shape was observed on 33 mandibles (82.5\%). The other 7 were rounded in shape and accounted for $17.5 \%$.
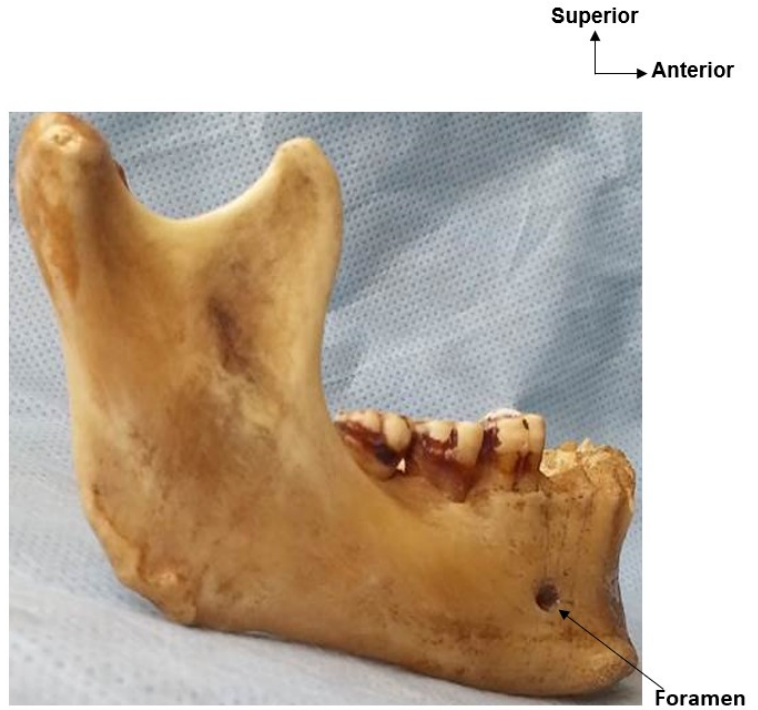

Fig. 5: Right lateral view of a mandible with a rounded mental foramen.

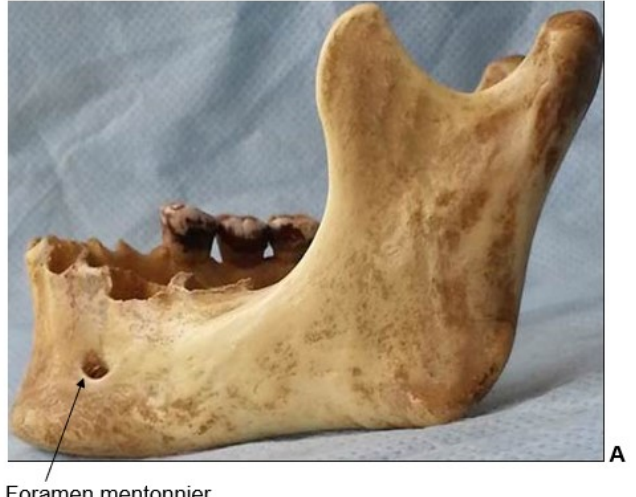

Foramen mentonnie

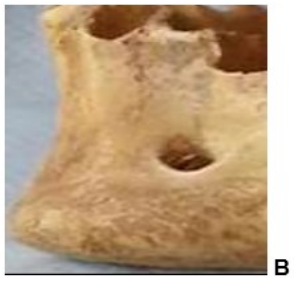

Fig. 6: Oval-shaped mental foramen in a left lateral view of a mandible.

A: Entire mandible B: View centered on the mental foramen

Position of the mental foramen in relation to the lower teeth: On the right, the type III situation was encountered in 25 cases (4.1\%), type IV in 8 cases (20.5\%) and type II in 6 cases (15.4\%) (Figure 7).
On the left, the type III situation was observed in 25 cases $(62.5 \%)$, type II in 9 cases $(22.5 \%)$ and type IV in 6 cases (15\%) (Figure 8). On the right as on the left, situations of type I and $V$ were not observed.

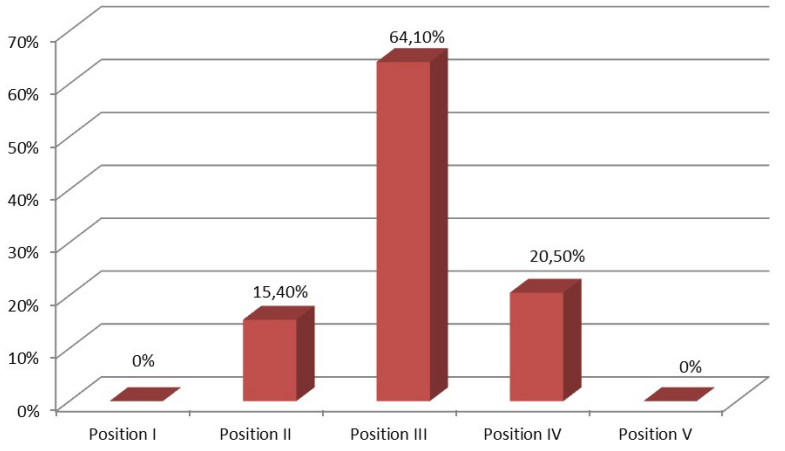

Fig. 7: Distribution of the mandibles according to the location of the foramen in relation to the lower teeth on the right $(n=39)$.

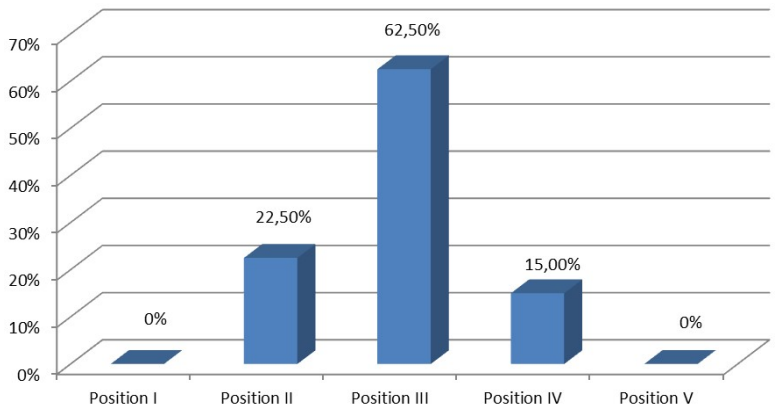

Fig. 8: Distribution of the mandibles according to the location of the foramen in relation to the lower teeth on the left $(n=40)$.

Location of the foramen in relation to the other landmarks of the mandible (Table 1)

Situation in relation to the chin symphysis (A): On the right, the distance $A$ ranged from $21 \mathrm{~mm}$ to $30 \mathrm{~mm}$ with an average distance of $25 \mathrm{~mm}$ and a standard deviation of 2.18. On the left, it ranged from $20 \mathrm{~mm}$ to $29 \mathrm{~mm}$ with an average distance of $25 \mathrm{~mm}$ and a standard deviation of 2.13 .

Situation in relation to the basilar border (B): On the right, the distance $B$ ranged from $10 \mathrm{~mm}$ to $20 \mathrm{~mm}$ with an average distance of $13 \mathrm{~mm}$ and a standard deviation of 2.1. On the left, it ranged from $14 \mathrm{~mm}$ to $17 \mathrm{~mm}$ with an average distance of $14 \mathrm{~mm}$ and a standard deviation of 1.77 .

Situation in relation to the posterior edge of the mandible $(\mathrm{C})$ : On the right, the mean distance $C$ ranged from $53 \mathrm{~mm}$ to $82 \mathrm{~mm}$ with an average distance of $72 \mathrm{~mm}$ and a standard deviation of 5.73 . 
On the left, it ranged from $53 \mathrm{~mm}$ to $83 \mathrm{mmn}$ with an average distance of $73 \mathrm{~mm}$ and a standard deviation of 6 .

Table 1: Distance between the mental foramen and the other landmarks of the mandible.

\begin{tabular}{cccc}
\hline $\begin{array}{c}\text { Mental } \\
\text { Foramen }\end{array}$ & $\begin{array}{c}\text { Distances } \\
(\mathbf{m m})\end{array}$ & Limits & Means \\
\hline \multirow{2}{*}{ Right side } & A & $21-30$ & 25 \\
& B & $10-20$ & 13 \\
& C & $53-82$ & 72 \\
Left side & A & $20-29$ & 25 \\
& B & $14-17$ & 14 \\
& C & $\mathbf{5 3 - 8 3}$ & $\mathbf{7 3}$ \\
\hline
\end{tabular}

A: Distance mental foramen-mandibular symphysis B: Distance mental foramen-basilar edge of the body of the mandible

C: Distance mental foramen-posterior edge of the ipsilateral branch

Table 2: Vertical diameters of the mental foramina ( $n=79$ ).

\begin{tabular}{cccc}
\hline $\begin{array}{c}\text { Mental } \\
\text { Foramen }\end{array}$ & $\begin{array}{c}\text { Diameters } \\
(\mathbf{m m})\end{array}$ & Number & Percentage (\%) \\
\hline \multirow{4}{*}{ Right side } & 2 & 9 & 23,1 \\
& 3 & 12 & 30,8 \\
& 4 & 15 & 38,4 \\
\hline \multirow{4}{*}{ Left side } & 5 & 3 & 7,7 \\
\hline & Total & $\mathbf{3 9}$ & $\mathbf{1 0 0}$ \\
\hline & 2 & 11 & 27,5 \\
& 3 & 15 & 37,5 \\
& 5 & 11 & 27,5 \\
& 6 & 2 & 5 \\
\hline & Total & $\mathbf{4 0}$ & $\mathbf{1 0 0}$ \\
\hline
\end{tabular}

Table 3: horizontal diameters of the mental foramina $(n=79)$

\begin{tabular}{cccc}
\hline $\begin{array}{c}\text { Mental } \\
\text { foramen }\end{array}$ & $\begin{array}{c}\text { Diameters } \\
(\mathbf{m m})\end{array}$ & Number & Percentage (\%) \\
\hline \multirow{3}{*}{ Righ side } & 2 & 2 & 5,1 \\
& 3 & 7 & 18 \\
& 5 & 17 & 43,6 \\
& Total & $\mathbf{3 9}$ & $\mathbf{1 0 0}$ \\
\hline & 2 & 4 & 10 \\
Left side & 3 & 12 & 30 \\
& 4 & 11 & 27,5 \\
& 5 & 10 & 25 \\
& 6 & 3 & 7,5 \\
\hline & Total & $\mathbf{4 0}$ & $\mathbf{1 0 0}$ \\
\hline
\end{tabular}

\section{Diameters}

Vertical diameter (Table 2): On the right, the vertical diameter ranged from $2 \mathrm{~mm}$ to $5 \mathrm{~mm}$ with an average diameter of $3.3 \mathrm{~mm}$ and a standard deviation of 0.9. On the left, it ranged from $2 \mathrm{~mm}$ to $6 \mathrm{~mm}$ with an average diameter of $3.2 \mathrm{~mm}$ and a standard deviation of 1 .

Horizontal diameter (Table 3): On the right, the horizontal diameter ranged from $2 \mathrm{~mm}$ to $6 \mathrm{~mm}$ with an average diameter of $4 \mathrm{~mm}$ and a standard deviation of 0.9. On the left, it ranged from $2 \mathrm{~mm}$ to $6 \mathrm{~mm}$ with an average diameter of $4 \mathrm{~mm}$ and a standard deviation of 1.1 .

\section{DISCUSSION}

Methodology: The mental foramen has already been the subject of several studies in different countries and different ethnic groups. To better compare our work with previous studies, we use a methodology already described and often used [14, 5, 6, 13].

We use bone anatomical landmarks, which are therefore fixed and therefore reliable. Some authors $[11,15]$ have made a study on radiographs. Because, unlike other foramina, the mental foramen is generally visible in conventional radiology and in panoramic radiography (orthopantomogram). Digital volumetric tomography currently makes it possible to accurately visualize the topographic location of the mental foramen in relation to neighboring dental roots, as well as pathological changes in adjacent bone, and to accurately measure all clinically relevant distances [2].

Results: In our study, the prevalence of single mental foramina is $100 \%$ on the right and $97.43 \%$ on the left. Only one double foramen was found and no triple or quadruple foramen.

Duplication of the mental foramen is the most common variation in number. The prevalence provided varies from 1.4 to $12.5 \%$ [16].

UDAYA [17] in his study on the Indian population observed $96.67 \%$ of unique foramina on the left and $97.78 \%$ on the right, therefore more supernumerary foramina (all double). He used a larger sample than ours for his study, which may explain why he found more double foramina.

No mandible with an absence of foramen was observed in our study. However, rare cases of absence of mental foramen have been reported in the literature $[18,19]$.

Shape: The oval shape is the most observed 
with a proportion of $82 \%$. For all the mandibles studied, the shape observed on the right is the same as that observed on the left except for the mandible with a double foramen on the left. On this one, the two foramina on the left are oval and the foramen on the right is rounded.

The clear predominance of oval-shaped FM is also noted MBAJIORGU [20], in the study on the Zimbabwean population with a proportion of $74.3 \%$. It is the same for GERHENSON [21] among the Israelis. Only SINGH [22] notes the predominance of the rounded shape in the Indian population with a frequency of $94 \%$.

FM has a variable shape depending on the intraosseous path of the chin pedicle [10]:

- in the oval type, the incisal pedicle is in the extension of the mandibular pedicle which emits a chin pedicle either up and behind (small oval type), or laterally (large oval type). We can also describe an incisor type: the mandibular pedicle comes out of the foramen and gives an incisor branch which returns in the body by a distinct foramen located in front; - in the round type, the mandibular pedicle has a deeper path in the mandibular body; the incisor branch continues forward intraosseously while the chin branch follows a backward path up and out;

- in multiple forms ( 2 to $8 \%$ ) the mental nerve divides early into labial and chin branches which take different foramina.

\section{Situation in relation to the lower teeth:}

In our study, the type III situation is the most observed. WANG [13], GREEN [5] and SANTINI [6] also describe this situation as being the most frequent. The type II situation is most observed in the Turkish population [14].

These results corroborate the data in the literature. Because, on the sagittal plane, the mental foramen is most often located below the second premolar (in 18 to $78 \%$ of cases) or below the intermediate space between the two premolars (in 6 to $60 \%$ cases) [2].

However, WANG [13], GREEN [5] and SANTINI [6] demonstrate that there are racial differences between Chinese and English [9] and other ethnic groups $[5,13]$.
We found no situation I and $V$ foramen similar to work done in Russia [23], Japan [24] and East Africa [9].

\section{Location of the foramen in relation to the other} landmarks of the mandible

Distance foramen-chin symphysis: The average distance $A$ is $25 \mathrm{~mm}$ on the right and on the left in our study.

Distance foramen-basilar edge of the mandible: The average distance $B$ is $13 \mathrm{~mm}$ on the right and $14 \mathrm{~mm}$ on the left.

For these two distances, our results agree with those found in previous studies. Indeed, the measurements of the mandibular bodies indicate, according to the studies, an average distance of 22.0 to $28.0 \mathrm{~mm}$ from the mental foramen to the center of the mandible, from 12.0 to $15.6 \mathrm{~mm}$ from the mental foramen to the inferior border. of the mandible [2].

\section{Distance foramen-posterior edge of the} mandible: The average distance $C$ is $72 \mathrm{~mm}$ on the right and $73 \mathrm{~mm}$ on the left.

Our results are very close to those found in studies on the Chinese population $[13,1]$ $174.11 \mathrm{~mm}$ on the right and $74.17 \mathrm{~mm}$ on the left). In the study of the Indian population [30], this distance is longer on the right $(84.7 \mathrm{~mm})$.

Diameters: The average vertical diameter is $3.3 \mathrm{~mm}$ on the right and $3.2 \mathrm{~mm}$ on the left and less than the horizontal diameter which average $4 \mathrm{~mm}$ on both sides. Most of the FM found had an oval shape.

In the study carried out in Malawians [25], the same measurements are made. The following results are noted: the average vertical diameter is $2.43 \mathrm{~mm}$ on the right and $2.71 \mathrm{~mm}$ on the left and the average horizontal diameter is $5.5 \mathrm{~mm}$ on the right and $5 \mathrm{~mm}$ on the left.

\section{CONCLUSION}

FM provides passage to the vessels and the mental nerve, hence its importance in dentistry and oral surgery. This is a constant anatomical structure, found on all the mandibles studied, bilaterally, more or less symmetrically.

Overall, our results are consistent with those published in the majority of studies on the 
mental foramen. However, some variations are noted, hence the importance of making a good localization of the mental foramen before any intervention on the lower teeth and the oral region. A mental nerve injury that can pose a real forensic problem.

\section{REMERCIEMENTS}

Our thanks go to the research team in anthropology and cultural engineering (URICA) led by Professor THIAW.

\section{Conflicts of Interests: None}

\section{REFERENCES}

[1]. Rouvière H, Delmas A. Anatomie humaine descriptive, Tome I: tête et cou. 15 éd. Paris : Masson; 2002:654.

[2]. VON ARX T. Le foramen mentonnier, "le carrefour de la mandibule" une observation anatomoclinique. Rev Mens Suisse odontostomatol. 2013;123(3):2016-2025.

[3]. Marzola C. Anesthesiologia. 1ed. Sao Paulo:Pancast Editorial ; 1989:1231.

[4]. Morrant G M. A biometric study of the human mandible. Biometrika. 1936;28:84-122.

[5]. Green R.M. The position of the mental foramen: a comparison between the southern (Hong Kong) Chinese and other ethnic groups. Oral Surg Oral Med Oral Path. 1987;63:287-90.

[6]. Santini A., Land M. A comparison of the position of the mental foramen in Chinese and British mandibles. Acta Anat. 1990;37:208-12.

[7]. Agarwal D R, Gupta S B. Morphometric analysis of mental foramen in human mandibles of South Gujarat peoples. J Sci Res.2011(4):15-18.

[8]. Gutman A D, Laufer D. Anesthesia following endodontic overfilling with AH26. Oral Surg. 1981;52:554-6.

[9]. Zivanovic S. Some morphological characters of the East African mandibles. Acta Anat. 1970;77: 109-19.

[10].Gaudy FF, Cannas B, Gillo L, Gorce T. Atlas d'Anatomie implantaire. Elsevier Masson;2011.

[11]. Bouhoute M, Mezzour M, Bouziane A, El Harti K. Fréquence des variations anatomiques du foramen mentonnier évaluée par Cone Beam : revue systématique. Odontostomatol Trop. 2020:43: 49-66.

[12]. Frieman N, Levine H L. Mucogingival surgery: current status. J Periodont. 1964;355-21.
[13]. Wang T.M., Shih C., Liu J.C., Kuo K.J. A clinical and anatomical study of the location of the mental foramen in adult Chinese mandibles. Acta Anat .1986;126:29-33.

[14]. Aktekein M, Celik H M, Celik H H, Aldur M M, Aksit $M D$. Studies on the location of the mental foramen in Turkish mandibles. Morphologie. 2003;87:17-9.

[15]. Kalender A, Orhan K, Aksoy V. Evaluation of the mental foramen and accessory mental foramen in Turkish patients using Cone Beam Computed Tomography images reconstructed from a volumetric rendering program. Clin Anat $\mathrm{N} \mathrm{Y}$. 2012;25(5):584-592.

[16]. Borghesi A, Pezzoti S, Nocivelli G, Maroldi R. Five mental foramina in the same mandible: CBCT findings of an unusual anatomical variant. Surg Radiol Anat. 2018;40(6):635-40.

[17]. Udhaya K, Saraladevi K V, Sridar J. The morphometric analysis of the mental foramen in adult dry mandibles: a study on the South Indian population. J Clin Diagn Research. 2013;7:1547-51.

[18]. De Freitas V, Madeira M C, Toledo Filho J L, Chagas C F. Absence of the foramen mental in dry human mandibles. Acta Anat. 1979; 1100:353-55.

[19]. Hassan T, Fauzi M, Hasan D. Bilateral absence of mental foramen: a rare variation. Int J Anat Var.2010(3):187-189.

[20]. Mbajiorgu E F, Mawera G, Asala S A, Zivanovi S. Position of the mental foramen in adult Black Black Zimbabwean mandibles: a clinical and anatomical study. Central Afr J Med. 1998;44:24-30.

[21]. Gerhenson A, Nathan H, Luchansky E. Mental foramen and mental nerve: changes with age. Acta Anat .1986;126:21-28.

[22]. Singh R, Srivastava A K. Study of position, shape, size and incidence of mental foramen and accessory mental foramen in Indian adult human skulls. Int J Morphol. 2010;28:1141- 6.

[23]. Kuznetsova L V, Smirnov V G. Individual variability of the form and position of the mandibular and mental foramina. Stomatologiia (Mosk). 1969;48:54-7.

[24]. Akabori K. Foramen mentale. Anatomy, section 1. Crania niponnica recentia, section J. Jpn J Med SciBiol.1934;4:296-303.

[25]. Igbigbi P S, LEBONA S. The position and dimensions of the mental foramen in adult Malawian mandibles. West Afri J Med. 2005;24:184-9.

How to cite this article:

Ndiaye M R, Mar N B, Yacouba Garba K, Ndoye J M N. Mental foramen of Human Mandible: Morphometric Study. Int J Anat Res 2021;9(4):8109-8115. DOI: 10.16965/ijar.2021.164 